\title{
PENGEMBANGAN MEDIA PEMBELAJARAN PREZI BERBASIS MNEMONIC PADA MATERI KLASIFIKASI MAKHLUK HIDUP
}

\author{
Fauzul Iman', Irva Faoji Anwar², Lia Junita Harahap ${ }^{3}$, Septia Ningsih ${ }^{4}$, Mieke Miarsyah ${ }^{5}$, \\ Rizhal Hendi Ristanto ${ }^{6}$
}

Magister Pendidikan Biologi, Universitas Negeri Jakarta

Corresponsing Author: fauzuliman04@yahoo.co.id, septianingsih3103@gmail.com

\begin{abstract}
ABSTRAK
Penggunaan media pembelajaran yang terintegrasi teknologi diharapkan dapat mempermudah dalam menyampaikan informasi. Selain itu juga diharapkan dapat terjadinya proses pembelajaran yang interaktif. Salah satu pembelajaran yang interaktif yaitu media pembelajaran prezi. Media pembelajaran prezi akan lebih interaktif apabila berbasis mnemonic. Materi yang sesuai untuk media pembelajaran yang berbasis mnemonic adalah klasifikasi makhluk hidup, karena materi klasifikasi makhluk hidup membutuhkan media pembelajaran yang dapat mengurutkan tingkatan takson. Tujuan penelitian adalah mengetahui pengembangan dan kelayakan dari media pembelajaran prezi. Penelitian ini adalah penelitian pengembangan (Research and Development) media prezi berbasis mnemonic dimodifikasi dari model R \& D dari Borg and Gall. Validasi oleh ahli materi mendapat kriteria sangat baik dengan persentase sebesar $88 \%$, validasi oleh ahli media mendapat kriteria sangat baik dengan persentase sebesar $92 \%$, dan validasi oleh ahli bahasa mendapat kriteria sangat baik dengan persentase sebesar $84 \%$. Uji coba produk dilakukan oleh 22 orang peserta didik, mendapat kriteria sangat baik dengan persentase sebesar 90,98\%. Hal ini menunjukan bahwa media prezi berbasis mnemonic valid dan layak digunakan dalam pembelajaran pada materi klasifikasi makhluk hidup.
\end{abstract}

Kata Kunci: Prezi, Mnemonic, Model R \& D, Validasi, Uji Coba

\begin{abstract}
The use of technology-integrated learning media is expected to make it easier to convey information. It is also expected that interactive learning processes can occur. One interactive learning is prezi learning media. Prezi learning media will be more interactive if it is based on mnemonic. The material suitable for learning media based on mnemonic is the classification of living things, because the material classification of living things requires learning media that can rank taxon levels. The purpose of the study was to determine the development and feasibility of the prezi learning media. This research is a research and development (mnemonic-based prezi media) modified from the R\&D model of Borg and Gall. Validation by material experts got very good criteria with a percentage of $88 \%$, validation by media experts got very good criteria with a percentage of $92 \%$, and validation by linguists got very good criteria with a percentage of $84 \%$. The product trial was conducted by 22 students, getting very good criteria with a percentage of $90.98 \%$. This shows that mnemonic-based prezi media is valid and feasible to be used in learning on the classification of living things.
\end{abstract}

Keywords: Prezi, Mnemonic, $R \&$ D Model, Validation, Trial

\section{PENDAHULUAN}

Perkembangan teknologi memberikan dampak besar terhadap mutu pendidikan di Indonesia. Teknologi seyogyanya dijadikan sebagai media dalam proses pembelajaran. Hal ini sejalan dengan proses pembelajaran abad 21 yang menekankan pada penggunaan tekno-logi dalam proses belajar mengajar. Penggu-naan media pembelajaran yang terintegrasi teknologi diharapkan dapat mempermudah da-lam menyampaikan informasi. Selain itu juga diharapkan dapat terjadinya proses pembela-jaran yang interaktif. Menurut Arsyad (2009) pemanfaatan media dalam pembelajaran dapat membangkitkan kei- 
nginan dan minat baru, meningkatkan motivasi dan rangsangan belajar dan bahkan berpengaruh secara psikologis kepada peserta didik. Manfaat media pembelajaran yaitu mampu memperjelas pesan agar tidak terlalu verbalitis, mengatasi keterbatasan ruang, waktu, tenaga dan daya indera, menimbulkan semangat belajar serta memberikan rangsangan pengalaman dan menimbulkan persepsi yang sama (Antika, 2016). Salah satu manfaat media pembelajaran di kelas adalah sebagai media presentasi. Banyak media presentasi yang dapat dipakai saat ini, presentasi dengan menggunakan media pembelajaran yang inovatif akan menciptakan kegiatan pembelajaran yang lebih interaktif.

Salah satu pembelajaran yang interaktif yaitu media pembelajaran prezi. Prezi merupakan software presentasi yang juga dirancang agar dapat menampilkan media visual, audio maupun animasi. Prezi dikembangkan pada tahun 2007 dan dipublikasi pada tahun 2009 oleh seorang seniman yang berasal dari Hungaria yaitu Adam Somlai-Fischer dan seorang ahli komputer yaitu Peter Halacsy (Surani, 2017). Menurut Wardani (2015), prezi adalah sebuah software yang dapat membantu membuat slide untuk presentasi yang menarik dan kreatif secara online. Berbeda dari powerpoint prezi memberikan ruang/kanvas yang cukup luas untuk menuangkan ide kreatif pembuat slide (Chou, 2015).

Prezi memberikan kesempatan kepada pengguna untuk menampilkan informasi dan keterampilan yang tinggi dan tata ruang yang dinamis (Artianningsih, 2013). Prezi memberikan ruang yang lebih bebas untuk menuangkan kreasi dan ide dalam pembuatan slide presentasi. Salah satu keunggulan prezi adalah menggunakan Zooming User Interface (ZUI), yang memungkinkan pengguna prezi untuk memperbesar dan memperkecil tampilan media presentasi (Prayoga, 2013).

Kelebihan dari media presentasi prezi adalah adanya zoomable canvas sehingga dapat memfokuskan slide ke setiap kalimat dengan pergerakan slide yang cukup dinamis dan variatif (Kiss, 2016). Media prezi dapat menyisipkan gambar, foto ataupun video kedalam slide juga menunjang kemudahan dalam menyusun slide presentasi yang diinginkan (Febrianto, 2017). Penggunaan media prezi dapat membuat proses pembelajaran lebih menyenangkan dan informatif serta meningkatkan kualitas belajar (Burhanudin, 2018). Pembelajaran menggunakan prezi lebih baik dari pada hanya menerangkan tanpa menggunakan media apapun (Argagini, 2018). Dengan adanya pembelajaran menggunakan prezi, peserta didik akan lebih tertarik terhadap pembelajaran, sehingga proses pembelajaran lebih berkualitas. Materi juga akan lebih tersusun secara sistematis, sehingga mempermudah guru pada saat menjelaskan materi. Media pembelajaran prezi akan lebih interaktif apabila berbasis mnemonic.

Mnemonic adalah strategi mengorganisasikan informasi secara visual atau verbal (Saguni, 2006). Metode mnemonik atau sering disebut jembatan keledai merupakan metode untuk meningkatkan daya ingat (Ardika, 2016). Peserta didik diharapkan dapat mengetahui informasi secara mendalam yang didapat secara visual atau verbal. Menurut Ansrulloh (2008), mnemonic merupakan strategi yang dipelajari untuk mengoptimalkan kinerja ingatan. Mnemonic memberikan kemudahan dalam mengingat, dengan mengambil beberapa suku kata atau huruf dalam beberapa kata, kemudian dibentuk dalam kalimat yang menarik untuk memudahkan dalam mengingat.

Klasifikasi makhluk hidup adalah pengelompokan makhluk hidup berdasarkan persamaan ciri yang dimiliki dengan tujuan untuk menyederhanakan obyek yang beraneka ragam. Semua ahli biologi menggunakan suatu sistem klasifikasi untuk mengelompokkan tumbuhan ataupun hewan yang memiliki persamaan struktur, kemudian setiap kelompok tumbuhan ataupun hewan tersebut dipasang-pasangkan dengan kelompok tumbuhan atau hewan lainnya yang memiliki persamaan dalam kategori lain (Kurniawan, 2015). Pada tahun 1969 RH Whittaker membagi sistem klasifikasi makhluk hidup menjadi lima kingdom berdasarkan tipe sel, jumlah sel dan tipe nutrisi, yakni kingdom Monera, Protista, Fungi, Plantae dan Animalia (Rohwati, 2012). 
Penelitian sebelumnya yang dilakukan Anshorulloh (2008) dalam hasil penelitiannya mengungkapkan bahwa pembelajaran dengan menggunakan metode mnemonic dapat meningkatkan daya ingat siswa. Berdasarkan beberapa hasil penelitian yang telah dilakukan peneliti sebelumnya, Richmond, Cummings, dan Klapp (2008) dalam Sudirman (2017) meneliti tentang transfer pengetahuan deklaratif menggunakan metode loci, pegword, dan keyword mnemonic pada 108 siswa SMP kelas IPA VIII. Penelitian bertempat di Nevada, Amerika Serikat yang menunjukkan bahwa metode keywords mnemonic dapat digunakan untuk mentransfer pengetahuan deklaratif (declarative memory) lebih baik daripada metode loci dan pegwords. Mnemonic dapat diterapkan pada materi klasifikasi makhluk hidup, materi klasifikasi makhluk memerlukan ingatan yang kuat saat mempelajari tingkatan takson.

\section{METODE PENELITIAN}

Penelitian ini dilaksanakan di SMK Kesehatan Fahd Islamic School pada tahun ajaran 2018/2019. Penelitian pengembangan (Research and Development) media prezi berbasis mnemonic dimodifikasi dari model $\mathrm{R} \& \mathrm{D}$ dari Borg and Gall (2003). Langkah-langkah pengembangan model Borg and Gall dijelaskan pada Gambar 1.

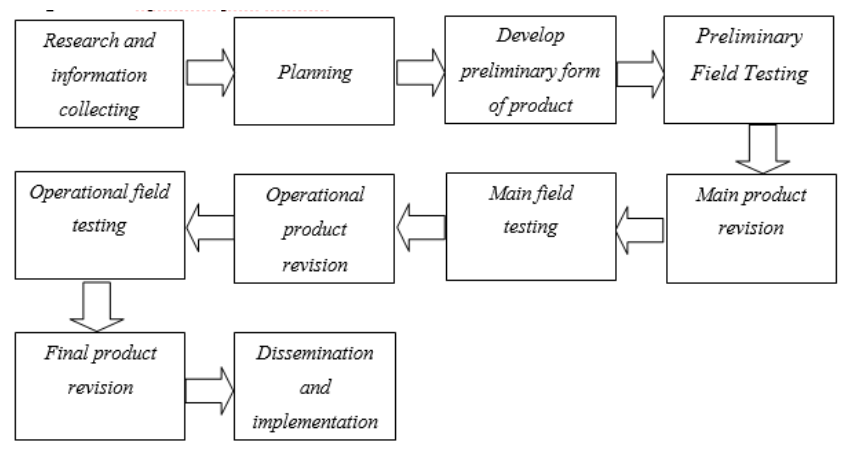

Gambar 1. Langkah-langkah Penelitian Pengembangan Model
Borg and Gall

Penelitian ini dilakukan hanya pada langkah revisi uji coba awal (main product revision) dikarenakan keterbatasan waktu. Berikut lang- kah-langkah penelitian pengembangan model Borg and Gall:

1. Studi Pendahuluan (Research and Information Collecting)

Langkah ini meliputi analisis kebutuhan peserta didik terhadap media pembelajaran yang terdapat di sekolah. Peserta didik yang membutuhkan media pembelajaran yang lain, maka perlu dikembangkan media pembelajaran baru. Pengembangan media pembelajaran perlu disesuaikan dengan karakteristik dari peserta didik.

2. Perencanaan (Planning)

Langkah ini meliputi merencanakan media pembelajaran yang dikembangkan, baik dalam merencanakan biaya yang akan dikeluarkan maupun lama waktu yang dibutuhkan dalam pengembangan media.

3. Pengembangan Desain (Develop Preliminary of Product)

Langkah ini meliputi menentukan desain produk yang akan dikembangkan, serta sarana dan prasarana yang akan dibutuhkan dalam pengembangan media pembelajaran

4. Uji Coba Awal (Preliminary Field Testing) Langkah ini meliputi uji validitas yang dilakukan oleh para validator. Penelitian ini terdapat 3 uji validasi, yaitu validasi ahli materi oleh Ibu Intan Purnamasari, S.Pd, ahli media oleh Bapak Yudhistira Adi Nugraha, S.Pd, dan ahli bahasa oleh Ibu Kus Rekhanah, S.Pd. Semua validator merupakan guru yang ada di SMK Kesehatan Fahd Islamic School dan uji coba awal kepada peserta didik kelas X sebanyak 22 orang.

\section{Revisi Hasil Uji Coba (Main Product Revision)}

Langkah ini meliputi memperbaiki media prezi berbasis mnemonic berdasarkan kritik dan saran yang diberikan oleh para validator.

Teknik analisis data dilakukan berdasarkan hasil dari instrumen validasi media prezi berbasis mnemonic menggunakan skala likert dengan 5 pilihan jawaban, yaitu sangat setuju (SS), setuju (S), tidak berpendapat (TB), tidak setuju (TS), dan sangat tidak setuju (STS) (Arikunto, 2015). Rumus untuk mengetahui persentase hasil dari suatu instrumen sebagai berikut: 


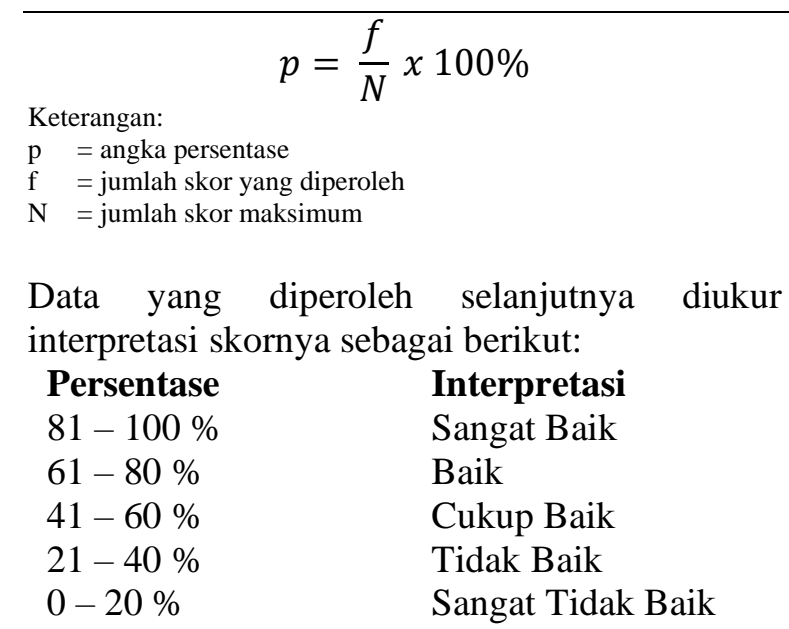

(Arikunto, 2015)

\section{HASIL DAN PEMBAHASAN}

Pengembangan media pembelajaran prezi berbasis mnemonic pada materi klasifikasi makhluk hidup dilakukan sesuai dengan tahapan pada model pengembangan Borg and Gall.

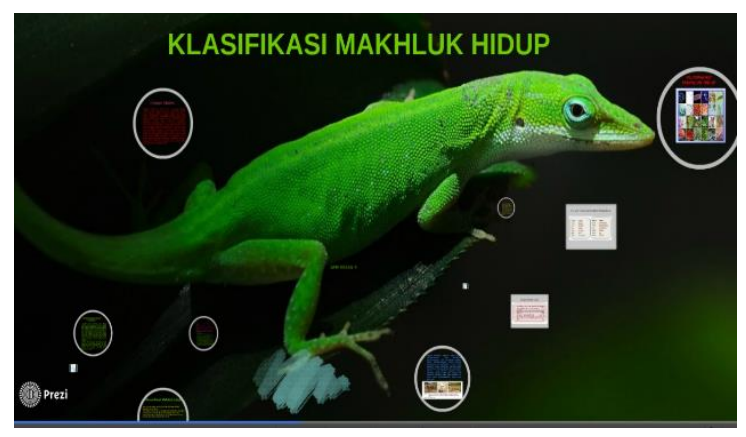

Gambar 2. Tampilan utama media pembelajaran prezi berbasis mnemonic

Kelebihan dari media presentasi prezi adalah adanya zoomable canvas sehingga dapat memfokuskan slide ke setiap kalimat dengan pergerakan slide yang cukup dinamis dan variatif (Kiss, 2016). Penelitian ini dibatasi hanya sampai tahapan uji coba produk pada peserta didik kelas X. Validasi media pembelajaran prezi dilakukan oleh para ahli, yaitu ahli materi, ahli media, dan ahli bahasa. Validasi dilakukan dengan memberikan instrumen yang memiliki skor 1-5.
Tabel 1 Validasi Produk oleh Para Ahli

\begin{tabular}{cccc}
\hline \hline No. & Aspek & Persentase & Kategori \\
\hline 1. & Materi & $88 \%$ & Sangat Baik \\
2. & Media & $92 \%$ & Sangat Baik \\
3. & Bahasa & $84 \%$ & Sangat Baik \\
Rata-rata & $88 \%$ & Sangat Baik \\
\hline \hline
\end{tabular}

Validasi oleh ahli materi mendapat kriteria sangat baik dengan persentase sebesar $88 \%$. Hal ini menunujukan bahwa media prezi yang dikembangkan telah memiliki informasi yang jelas dan mudah dimengerti, sehingga dapat digunakan oleh peserta didik. Materi yang disajikan dalam media prezi telah sistematis sesuai dengan indikator dan tujuan pembelajaran yang harus dipelajari peserta didik. Menurut Mulyasa (2006), bahwa materi pembelajaran disajikan secara logis dan sistematis, sehingga peserta didik dalam menggunakan media pembelajaran tidak mengalami kesulitan, dan tidak menimbulkan pertanyaan mengenai yang harus dipelajari.

Validasi oleh ahli media mendapat kriteria sangat baik dengan persentase sebesar $92 \%$. Hal ini menjukkan bahwa desain media prezi yang dikembangkan sudah baik dan menarik meliputi bentuk dan ukuran huruf yang sesuai, gambar yang disajikan menarik dan relevan dengan materi, serta pemilihan warna yang sesuai dan menarik. Media prezi yang menarik akan mudah menarik perhatian peserta didik untuk menggunakannya. Hal ini sesuai dengan pendapat Arsyad (2009), bahwa dalam pemilihan ukuran huruf harus sesuai dengan peserta didik, pesan, dan lingkungannya.

Validasi oleh ahli bahasa mendapat kriteria sangat baik dengan persentase sebesar $84 \%$. Aspek kebahasaan berkenaan dengan penggunaan bahasa dan kalimat yang jelas, sehingga tidak menimbulkan kerancuan dan mudah dimengerti oleh peserta didik. Dalam penulisan, penulis berusaha menggunakan bahasa dan kalimat yang jelas agar mudah dimengerti oleh peserta didik. Warsita (2008) menyatakan bahwa media pembelajaran harus disajikan dengan bahasa yang baik agar peserta didik mudah memahaminya.

Uji coba produk dilakukan oleh 22 orang peserta didik, mendapat kriteria sangat baik dengan persentase sebesar 90,98\%. Hal ini menun- 
jukan bahwa media prezi berbasis mnemonic layak digunakan dalam pembelajaran pada materi klasifikasi makhluk hidup. Kelebihan media pembelajaran prezi dapat menghubungkan dan memperkuat teori dengan tampilan navigasi, zooming, gambar, video animasi, yang dapat meningkatkan antusiasme belajar siswa melalui media interaktif, menyebabkan siswa mudah menjadi paham, belajar menjadi lebih giat dan termotivasi (Aotar, 2015).

\section{KESIMPULAN}

Berdasarkan penelitian yang telah dilakukan, maka telah dihasilkan media pembelajaran yang dikembangkan termasuk kedalam kategori sangat baik dengan persentase hasil penilaian masing-masing ahli materi $88 \%$ sangat baik, ahli media $92 \%$ sangat baik, dan ahli bahasa $84 \%$ sangat baik. Uji coba produk peserta didik, mendapat kriteria sangat baik dengan persentase sebesar 90,98\%. Hal ini menunjukan bahwa media prezi berbasis mnemonic valid dan layak digunakan dalam pembelajaran pada materi klasifikasi makhluk hidup.

\section{DAFTAR PUSTAKA}

Antika, Y, dan Bambang Suprianto. (2016). Pengembangan Media Pembelajaran Berbasis Prezi Sebagai Upaya Meningkatkan Hasil Belajar Siswa Kompetensi Dasar Aplikasi Rangkaian OP AMP Mata Pelajaran Rangkaian Elektronika Di SMK Negeri 2 Bojonegoro. Jurnal Pendidikan, 05 (2): $493-497$.

Anshorulloh, R. (2008). Efektivitas Metode Mnemonik dalam Meningkatkan Daya Ingat Siswa pada Mata Pelajaran Sejarah di MTS Persiapan Negeri Kota Batu. Skripsi tidak diterbitkan. Malang: Universitas Islam Negeri Malang.

Aotar, Adlim, dan Safrida. (2015). Penerapan Presentasi Media Prezi pada Materi Sistem Saraf Manusia Terhadap Keterampilan Berfikir Kritis Siswa Kelas XI SMA Negeri 2 Bukit. Jurnal EduBio Tropika, 3 (2): 51-97.

Ardika, Y, dan A. Sardjana. (2016). Efektivitas Metode Mnemonik Ditinjau dari Daya
Ingat dan Hasil Belajar Matematika Siswa SMK Kelas X. Jurnal Matematika Kreatif -Inovatif, 7 (1): 66-73.

Argagini, D. F, dan Y. Sulistyorini. (2018). Pengembangan Media Pembelajaran Berbasis Prezi pada Matakuliah Analisis Vektor. KALAMATIKA Jurnal Pendidikan Matematika, 3 (2): 209-222

Arikunto, S. (2015). Dasar-dasar Evaluasi Pendidikan, Edisi 2. Jakarta: Bumi Aksara.

Arsyad, A. (2009). Media Pembelajaran. Jakarta: Rajawali Press.

Artianningsih, S. Witurachmi, dan S. Sumaryati. (2013). Penerapan Mind Mapping dengan Media Prezi untuk Meningkatkan Prestasi dan Partisipasi Belajar Akuntansi. JUPE UNS, 2 (1): 39-48.

Borg, W. R dan M. D Gall. (2003). Educational Research: An Introduction, Seventh Edition. New York: Longman.

Burhanudin, R, dan Suyoso. (2018). Pengembangan Media Pembelajaran Presentasi Berbasis Software Prezi untuk Meningkatkan Motivasi dan Hasil Belajar Fisika Siswa SMA Kelas X. Jurnal Pendidikan Fisika,7 (1): 38-48.

Chou, P.N, C. C. Chang, dan P. F. Lu. (2015). Prezi Versus Powerpoint: The Effects Of Varied Digital Presentation Tools On Students' Learning Performance. Computers \& Education, 91: 73-82.

Febrianto, R. (2017). Analisis Penerapan Media Pembelajaran Prezi terhadap Hasil Belajar Siswa Kelas X TPHP Pada Mata Pelajaran Pengendalian Mutu Dalam Proses Pengolahan Di SMK Negeri 3 Takalar. Jurnal Pendidikan Teknologi Pertanian. 3 (2): 42-48.

Kiss, G. (2016). Ms Power Point vs Prezi in Higher Education. TOJET: The Turkish Online Journal of Educational Technology, 15 (3): 126-130.

Kurniawan, D, Aristoteles dan Ahmad Amirudin. (2015). Pengembangan Aplikasi Sistem Pembelajaran Klasifikasi (Taksonomi) dan Tata Nama Ilmiah (Binomial Nomenklatur) pada Kingdom Plantae (Tum- 
buhan) Berbasis Android. Jurnal Komputasi, 3 (2): 1-9.

Mulyasa, E. (2006). Kurikulum yang Disempurnakan. Bandung: PT. Remaja Rosdakarya.

Prayoga, A. M, S. Santoso, dan N. Hamidi. (2013). Penggunaan Media Prezi dan Metode Pembelajaran Snowball Throwing untuk Meningkatkan Prestasi Belajar Akuntansi. Jupe UNS, 1 (2): 1-8.

Rohwati, M. (2012). Penggunaan Education Game untuk Meningkatkan Hasil Belajar IPA Biologi Konsep Klasifikasi Makhluk Hidup. Jurnal Pendidikan IPA Indonesia, 1 (1): 75-81.

Saguni, F. (2006). Prinsip-Prinsip Kognitif Pembelajaran Multimedia: Peran Modality dan Contiguity terhadap Peningkatan Hasil Belajar. Insan, 8 (3): 150.
Sudirman, N.A, dan A. A Ridha. (2017). Efektifitas Keyword Mnemonic dalam Mempelajari Kosakata. Jurnal Ilmiah Psikologi Terapan, 5 (2): 226-235.

Surani (2017). Pengembangan Media Pembelajaran Prezi pada Mata Pelajaran Membuat Pola di SMK Awal Karya Pembangunan Galang. Jurnal Pendidikan Teknologi dan Kejuruan, 19 (1): 1-8.

Warsita, B. (2008). Teknologi Pembelajaran. Jakarta: Rineka Cipta.

Wardani, F.W.K (2015). Perbandingan Hasil Belajar Siswa dalam Penerapan Problem Based Learning dengan dan Tanpa Dukungan Media Prezi pada Pembelajaran Akutansi Kelas X Di SMK Negeri 2 Nganjuk. Jurnal Pendidikan Akuntansi, 3 (3): $1-6$. 